\title{
Materials of biological origin and biofuels: Small environmental footprint and epigenetic impact (Review)
}

\author{
ELENI PAPAKONSTANTINOU ${ }^{1}$, THANASIS MITSIS ${ }^{1}$, KONSTANTINA DRAGOUMANI $^{1}$, \\ ASPASIA EFTHIMIADOU ${ }^{2}$, FLORA BACOPOULOU ${ }^{3}$, GEORGE P. CHROUSOS ${ }^{3,4}$, \\ ELIAS ELIOPOULOS ${ }^{1}$ and DIMITRIOS VLACHAKIS ${ }^{1,3,4}$ \\ ${ }^{1}$ Laboratory of Genetics, Department of Biotechnology, School of Applied Biology and Biotechnology, \\ Agricultural University of Athens, 11855 Athens; ${ }^{2}$ Department of Soil Science of Athens, \\ Institute of Soil and Water Resources, Hellenic Agricultural Organization-Demeter, 14123 Lycovrisi; \\ ${ }^{3}$ University Research Institute of Maternal and Child Health and Precision Medicine, and \\ UNESCO Chair on Adolescent Health Care, National and Kapodistrian University of Athens, \\ 'Aghia Sophia' Children's Hospital, 11527 Athens; ${ }^{4}$ Division of Endocrinology and Metabolism, \\ Center of Clinical, Experimental Surgery and Translational Research, \\ Biomedical Research Foundation of The Academy of Athens, 11527 Athens, Greece
}

Received June 8, 2021; Accepted August 4, 2021

DOI: $10.3892 /$ ije.2021.6

\begin{abstract}
Human activity, specifically the overreliance on fossil resources, has had numerous adverse effects on the environment and an epigenetic impact on human health. The destabilization of the environment and the accumulation of waste have caused alterations in the stability of the human ecosystem, affecting the exposome and modifying the epigenetic mechanisms that control or deregulate human physiology. For example, the increasing use of plastics and the chemicals derived, have been shown to promote diseases by altering epigenetic patterns. Thus, there is a growing need for more environmentally- and human-friendly alternatives, also known as 'green products and fuels'. Environmental biotechnology aims to produce 'green' products and fuels through the use of living cells and cell-derived molecules. The solutions offered by this scientific discipline may include 'green' alternatives to chemical solvents, machine lubricants, plastics, machine fuel and batteries. Each of these alternatives has its own strengths and weaknesses that should be taken into consideration before being heralded as the successors of fossil-derived products. The present review article summarizes the current scientific knowledge on the epigenetic impact of the current environmental status and the benefit of these alternatives.
\end{abstract}

Correspondence to: $\mathrm{Dr}$ Dimitrios Vlachakis, Laboratory of Genetics, Department of Biotechnology, School of Applied Biology and Biotechnology, Agricultural University of Athens, 75 Iera Odos, 11855 Athens, Greece

E-mail:dimvl@aua.gr

Key words: environmental biotechnology, epigenetics, biobased solvents, biolubricants, bioplastics, biofuels, biobatteries

\section{Contents}

1. Introduction

2. Materials of biological origin

3. Biofuels

4. Biobatteries

5. Current applications of 'green' products

6. Conclusions and future perspectives

\section{Introduction}

The natural environment contains the Earth's living organisms, air, soil and water (1). Alterations in the natural environment may have profound effects on social and economic development, human health and lifestyle, as well as on biological processes through an epigenetic impact (2). Therefore, it is crucial to study alterations in the natural environment and develop approaches with which to mitigate or even reverse possible adverse effects produced. Human activities, such as urbanization and pollution have led to the occurrence of a number of changes in the natural environment (3). In particular, anthropogenic activities have caused severe alterations in the Earth's climate (4). The effects of climate change include extreme weather and climatic events, water and food scarcity, ocean acidification and rising sea levels, damage to ecosystems and biodiversity, the disruption of the social infrastructure, and may damage human health (5).

The environmental footprint is a metric used to study the association between humans and their natural environment, and to examine the effect a population's consumption or lifestyle has on the environment (6). Environmental footprints consider several parameters regarding the environment, such as climate change, ocean acidification and rising sea levels, water scarcity and pollution, land availability, chemical 
pollution and loss of biodiversity (7). By studying the environmental footprints of various human activities and product use, specific approaches can be developed to mitigate their negative effects on the environment. Several factors that have a negative effect on the environmental footprint may also have an immediate negative effect on human health. This effect is mainly achieved through epigenetic mechanisms. Epigenetics refers to information that exists beyond that encoded in the DNA sequence and helps transduce the inheritance of gene expression patterns without DNA sequence alteration (8). Several mechanisms underlie epigenetics, such as DNA methylation, histone modifications and interaction with non-coding RNA molecules (9). The effect that such factors may have on epigenetics is one of the main subject of a study field termed environmental epigenetics (10).

The majority of countries rely on fossil fuels, which consist of oil, coal and natural gas for their energy needs (11). Fossil fuel combustion by-products are some of the most significant contributors to climate change (12). In the early $2010 \mathrm{~s},>80 \%$ of human energy was derived from fossil fuels (13). Emissions from fossil fuels include carbon dioxide $\left(\mathrm{CO}_{2}\right)$, which plays an important role in the greenhouse effect (12). The greenhouse effect is a system that drives Earth's surface heating. Solar radiation passes mostly effortlessly through the atmosphere and heats the Earth's surface. Consecutively, energy is reemitted as infrared, a large part of which is absorbed by $\mathrm{CO}_{2}$ and water vapor in the atmosphere, thus acting as a blanket surrounding Earth. Under normal circumstances, the greenhouse effect maintains the planet's average surface temperature viable to humans. Excess $\mathrm{CO}_{2}$ produced by fossil fuels, though, enhances the natural greenhouse effect and warms the planet at an alarming rate (14). Moreover, fossil fuel extraction, transportation, distribution and waste management also have adverse effects on the environment (13). The necessity for sustainable energy, i.e., able to supply a growing global population needs without destroying the environment within which it is used, has become more than necessary (15). Additionally, fossil fuel burning produces large amounts of polycyclic aromatic hydrocarbons (PAHs). Early embryo exposure to PAHs results in alterations in DNA methylation levels, with a prime example being the hypermethylation of the acyl-CoA synthetase long chain family member 3 (ACSL3) gene promoter, which leads to the decreased expression of the mentioned gene. The aforementioned condition is associated with asthma symptoms in children (10).

Another human activity with a damaging environmental footprint is the extensive use of plastics (16). Although inexpensive, lightweight and durable, plastics pose a credible environmental threat (16). Some of the negative effects of the extensive use of plastics include waste accumulation in landfills and natural habitats, physical issues in wildlife due to ingestion or entanglement in plastic, chemicals seeping from plastic products and their subsequent transfer to wildlife and humans (17). Additionally, plastics used in various medical procedures may feature various pathogens, and their management and destruction have a severe environmental footprint (18).

The negative effects of the use of plastics do not only apply to the macroscopic level of the environmental footprint, but have also been implicated in a number of human pathogenies through an epigenetic effect. Chemicals used for manufacturing plastics, such as bisphenols and phthalates (plastics derived endocrine disruptors) have been shown to induce toxic epigenetic effects in both male and female fertility, affecting their reproductive ability and quality of gametes (19). Prenatal exposure to bisphenols and phthalates has been proven to promote epigenetic modifications in embryo development, resulting in offspring pathophysiology, with a significant association with an increased incidence of diseases, such as obesity, reproductive diseases and impaired brain development (20,21). The recent study by Engdahl et al (22) negatively associated cognitive functions with prenatal bisphenol $\mathrm{F}$ exposure, demonstrating lower IQ levels in 7-year-old children. Bisphenol-A (BPA), an estrogen mimic, is a widely studied plastic-derived chemical, that modifies epigenetic signs, and affects DNA methylation patterns and histone modifications, induces transcriptional modifications, regulates gene expression and affects miRNA expression (23). The BPA epigenetic risk has been linked to metabolic disorders, hepatic deficiencies, type II diabetes, cardiovascular diseases and hypertension risk, as well as to hormone-dependent cancers, such as breast and prostate cancer (24-28). BPA is also characterized as a potential risk factor for neurodevelopmental disorders, such as autism (29). Plastic-derived chemicals are major risk factors that are epigenetically involved in fetal, natal and offspring development, and in the progression of diseases, and in some cases have been shown to promote transgenerational inheritance (20). It is thus imperative to lessen plastic use and develop new materials with a smaller environmental footprint and minimize the adverse effects of their epigenetic impact.

Biotechnology is a multidisciplinary study field that makes use of varied tools and technologies to create products based on cells or cell-derived molecules (30). Environmental biotechnology, which studies topics, such as waste management, biodegradation and biofuel production, aims to mitigate a number of deleterious anthropogenic environmental alterations (31). Furthermore, incorporating information extracted from environmental epigenetics can help design products that also have no deleterious effect on human health. The present review article presents biotechnological alternatives that lessen some of the environmental concerns and epigenetic effects associated with the aforementioned products.

\section{Materials of biological origin}

The main goal in multiple scientific disciplines is to incorporate the functional properties of materials of biological origin into new materials. Materials of biological origin are of significant interest when it comes to designing environmentally friendly, also known as 'green' products. Biological feedstocks, specifically, can be used to produce solvent, plastic and lubricating oil alternatives (32).

Solvents are extensively used in the production of chemicals as media for chemical reactions and chemicals separation or purification (33). The majority of solvents are highly volatile, flammable, toxic and can cause severe air pollution (34). These solvent attributes cause a number of environmental concerns, which mainly focus on solvent synthesis, use and disposal (33). Furthermore, some industrial solvents, such as trichloroethylene (TCE) have been shown to be associated with various 
autoimmune diseases, including lupus and scleroderma. This association may be due to the fact that TCE exposure leads to differentially methylated $\mathrm{CpGs}$ in regions responsible for polycomb group proteins binding. These proteins' function is to regulate $\mathrm{T}$ effector cell expansion and differentiation (35). Biobased solvents are a possible solution to the environmental and health concerns presented by traditional chemical solvents. Biobased solvents are generally derived from agricultural crops rich in carbohydrates, such as corn, wheat, beets, or residual organic matter, and are generally less toxic and volatile than traditional chemical solvents (36). These characteristics of biobased solvents render them a 'greener' option than traditional chemical solvents. Alcohols produced through the fermentation of biomass include 1-butanol, oc-tan-2-ol and propane-1,3-diol, and can be used as solvents in numerous industrial processes and may aid the production of commercial antibiotics, vitamins, resins, paint coatings and adhesives (36). Another prime example of a biobased solvent is ethyl lactate, which is biodegradable and non-toxic, and showcases a low volatility. Ethyl lactate garnered by corn and soybeans through the fermentation of biomass and the reaction of two fermentation products, ethanol and lactic acid. Ethyl lactate is mainly used in the extraction of phytochemicals (37). Although extremely promising, it should be noted that not all biobased solvents are of no environmental consequence. For example, terpenes are toxic to fish, while obtaining acetic acid from corn carbohydrate leads to higher emissions of greenhouse gasses than the production of its' fossil fuel-based counterpart (37).

Lubricating oils are essential in machine and device operation, since they minimize friction, eliminate the scuffing of rubbing machine elements, help with machine cooling, have anti-corrosion properties, and wash away carbon deposits and microparticles (38). Lubricating oils are a mixture of base oils that are derived from crude oils and enriching additives, which are mostly products of an organic synthesis process (38). Crude oil is a fossil resource that consists of paraffinnic, cycloparaffinic and aromatic hydrocarbons, low percentages of sulfur, and traces of nitrogen and oxygen compounds (39). Crude oil exerts severe toxic effects on the environment (40). Additives provide lubricating oils with new useful properties, enhance their existing properties and improve product lifetime (41). Traditional additives include sulfonate, sulfide alkylphenols and dialkyl dithiophosphate, which cause detrimental environmental effects (42). Lubricants were also used to contain polychlorinated biphenyls (PCBs) up until the 1970s when they were banned; they functioned as endocrine disruptors which altered gene methylation and were shown to exert carcinogenic effects (43). The effect of PCBs on the environment and human health have instilled a cautionary approach in the production of lubricants or novel additives. The aforementioned information indicates that there is a need for 'greener' and healthier alternatives to both lubricating oils and their additives. Non-fossil-based natural oils are an enticing option when it comes to lubricants with a small environmental footprint. These so-called biolubricants include natural vegetable oils, such as rice bran oil, rapeseed oil and coconut oil. Biolubricants have exhibited potential as they are characterized by a high bioavailability, high biodegradability, the absence of toxic and polluting effects to the environment, and, with the right additives, identical lubrication properties to those of petrochemical lubricants (44). Moreover, nanomaterials can be used as environmentally friendly additives. A prime example are nano-additives based on reduced graphene oxide nanosheets, which display a cost-effective and relatively straightforward, environmentally friendly synthesis process (45).

The environmental and epigenetic impact of plastics has already been mentioned. Plastics are synthetic polymers consisting of small molecules, termed monomers, linked together in a repetitive manner (46). The vast majority of plastics are non-biodegradable and the monomers used to construct them are derived from fossil hydrocarbons (47). The aforementioned, in conjunction with the fact that synthetic polymers are produced on an enormous scale annually, renders the management of plastics and the development of 'greener' alternatives a main goal of environmental biotechnology (48). Additionally, and as already mentioned, since the majority of plastics release chemicals with estrogenic activity, their use may lead to the disruption of the function of the endocrine system of an organism, culminating in severe pathological conditions (49). Some of these endocrine disruptors have been shown to influence both the methylation of regions, including hormone response elements and mediators of histone modifications (50). Bioplastics appear to be an appealing alternative to traditional plastics. The term bioplastics refers to biodegradable plastic materials and/or plastics that are produced from renewable resources (51). It is also important to note that, although some bioplastics are produced from renewable natural resources, not all are biodegradable (52). Bioplastics based on fossil materials are designed by selecting the appropriate monomers, additives and the polymerization process in order to become biodegradable products (53). Such types of plastics include polycaprolactone (PCL), poly-butylene succinate (PBS) and polybutylene adipate (PBA) (52). Bioplastics based on renewable natural resources (biobased plastics) are produced through fermentation or chemical processes, or a mixture of biotechnological and chemical processes (54). Biodegradable biobased plastics include polylactic acid (PLA), polyhydroxyalkanoates (PHAs), succinic acid, 1,3-propanediol-based polymers, cellulose and starch $(52,54)$. Non-biodegradable biobased plastics are chemically identical to their fossil-based counterparts, and thus also exhibit identical chemical properties. These non-biodegradable biobased plastics are also known as 'drop-in plastics' due to their low need for major investment and include biobased polyethylene terephthalate (bio-PET) and biobased polyethylene (bio-PE). The selection of an appropriate bioplastic depends on several parameters, such as a the lifetime of a product and resistance to environmental influences (53). In the cases of plastics used for product packaging, biodegradable biobased plastics seem to be an enticing option with a small environmental footprint (55).

Apart from providing alternatives to traditional synthetic plastics, environmental biotechnology aims to address the issue of already existing plastic waste. The current methods of managing plastic waste are landfill depositing, recycling and incineration (56). These methods have severe drawbacks however. Specifically, plastics in landfills last for an extensive period of time and render the ground unfit for profitable use; plastic recycling is very costly, and incineration releases toxic gases into the environment (56). A proposed solution is the 
use of microorganisms and enzymes to degrade synthetic plastics. Several enzymes and microorganisms that act on synthetic polymers have plastic-degrading abilities (57). However, a current bottleneck exists in the initial degradation of robust polymers with a high molecular weight (48). Therefore, further research is required for the identification of novel depolymerases that render the initial breakdown of plastics more efficient (57). Nonetheless, current advances in synthetic biology may overcome such a hurdle by generating synthetic microorganisms with the desired plastic-degrading abilities (48).

\section{Biofuels}

As it has already been mentioned, fossil fuel extraction is relatively harmful to the environment and its combustion products have a severe impact on human health. Biofuels may be a 'green' alternative to traditional fossil fuel, with biofuel research markedly increasing over the past decades. Biofuel refers to fuel obtained by biomass through a chemical procedure as opposed to a slow geological process, such as common fossil fuel (58). Biofuels include bioethanol, biomethane, biodiesel and biobutanol (59). The production of biofuels involves organic biomass, which is thermally and chemically decomposed or fermented by microorganisms to produce liquid or gas fuels, such as ethanol, methane and hydrogen (59). The theoretical benefits of biofuels include a reduction in oil import dependency, a more secure energy supply, an increased socioeconomic support of rural areas, and a smaller environmental footprint (60). As regards the health-related effects of biofuel use, further research is warranted. A comparative study on biodiesel produced by waste cooking oil and conventional fossil diesel as diesel engine fuel demonstrated that the fractions of parent PAHs gradually decreased with the increasing biodiesel content in the blends, while the corresponding fractions of oxygenated and nitrated derivatives steadily increased, particularly for oxy-derivate PAHs (61). Biofuels are divided into different generations, depending on their origin and production method (Fig. 1) (62).

First-generation (1G) biofuels are produced primarily from food crops, such as grains, sugar canes and vegetable oils (63). 1G bioethanol, specifically, is, as of 2019, the main liquid biofuel produced worldwide (64). Although $1 \mathrm{G}$ biofuels appear to be a step towards energy production with a lower environmental footprint, their use garnered much controversy in the 21st century, since the use of food crops and oils to produce fuel had a negative impact on food quality and undermined food safety. Landowners may begin to disproportionally use their edible crops for fuel rather than for food production, which, in turn, may lead to a decreased food supply and subsequent increases in prices (63). Moreover, some $1 \mathrm{G}$ biofuel production pathways seem to offer no advantage when it comes to lowering greenhouse gas emissions due to nitrous oxide $\left(\mathrm{N}_{2} \mathrm{O}\right)$ emissions, peat oxidation in the case of cultivation on peatland soils and the use of fertilizers (65). Lastly, the high demand for $1 \mathrm{G}$ biofuels may lead to problematic changes in land use (64). The aforementioned information indicates that the sustainability of $1 \mathrm{G}$ biofuels is severely limited, although ethanol produced by sugar canes is a possible exception, since it meets biofuel sustainability criteria (66). It is important to mention though, that the production of $1 \mathrm{G}$ biofuels, such as sugarcane ethanol will continue to improve and may thus may continue to satisfy energy needs (66).

The aforementioned disadvantages of several $1 \mathrm{G}$ biofuels led to the development of more sustainable biofuels, which subsequently led to the development of second-generation $(2 \mathrm{G})$ biofuels. $2 \mathrm{G}$ biofuels use non-food lignocellulosic materials, such as dedicated energy crops including perennial grasses and short rotation forestry, woodchips from energy crops, agricultural and forest residues, and even low-valued municipal and industrial solid wastes as raw materials (67). $2 \mathrm{G}$ biofuels overcome the dilemma 'food vs. fuel' dilemma since they do not use edible crops, and thus do not negatively impact food production and quality. Additionally, certain $2 \mathrm{G}$ biofuels such as cellulosic ethanol from switchgrass and carbon-negative biofuels from low-input high-diversity grassland biomass require a lower agricultural input, i.e., less fertilizer, pesticide and energy (68). The main disadvantage of $2 \mathrm{G}$ biofuels is their production cost. $2 \mathrm{G}$ biofuels have a higher capital cost than $1 \mathrm{G}$ biofuels. At the same time, some estimations in the early 2010 s demonstrated that $2 \mathrm{G}$ biofuels may be two- to three-fold more expensive than petroleum fuels on an energy equivalent basis $(69,70)$. Moreover, several mechanical hurdles have prevented $2 \mathrm{G}$ biofuels from reaching their optimal productivity (60). Specifically, $2 \mathrm{G}$ biofuels face technical difficulties during pre-treatment processes, and the conversion of lignocellulosic materials is quite inefficient due to the complex structure of the materials (71). Thus, further research is required in order for $2 \mathrm{G}$ biofuels to reach their potential and become commercially enticing.

Third-generation (3G) biofuels aim to address the disadvantages of $2 \mathrm{G}$ biofuels by using algae-derived biomass as their energy source (71). Algae comprise a diverse group of species that include photosynthetic, oxygen-producing, unicellular, or multicellular organisms without embryophyte terrestrial plants and lichens (72). Algae biomass consists of biochemical molecules, such as carbohydrates, lipids and proteins (73). Algae biomass presents numerous advantages as a source of biofuel, such as the ability to grow throughout the year, the ability to grow under variable conditions and a high growth potential (74). Furthermore, processing algae biomass can provide a number of economically enticing co-products, such as ingredients for functional foods and cosmetics (75). Even so, biofuel produced from currently available algae species does not seem to be cost-competitive with traditional fossil fuels and thus, selective breeding and genetic engineering are required to provide economically viable strains (76).

Fourth-generation (4G) biofuels are based on raw materials that are the result of genetic engineering, metabolic engineering, and synthetic biology applications on algae and cyanobacteria (77). These biofuels have a number of advantages in comparison to $3 \mathrm{G}$ biofuels. $4 \mathrm{G}$ biofuels use biomass with an enhanced carbohydrate and lipid content for optimal energy production (78). Additionally, genetically engineered algae can exhibit an enhanced $\mathrm{CO}_{2}$ sequestration (79). Despite these promising abilities, though, $4 \mathrm{G}$ biofuels are in their early stage of development, and thus the investments needed to expand further the technology are relatively high. 


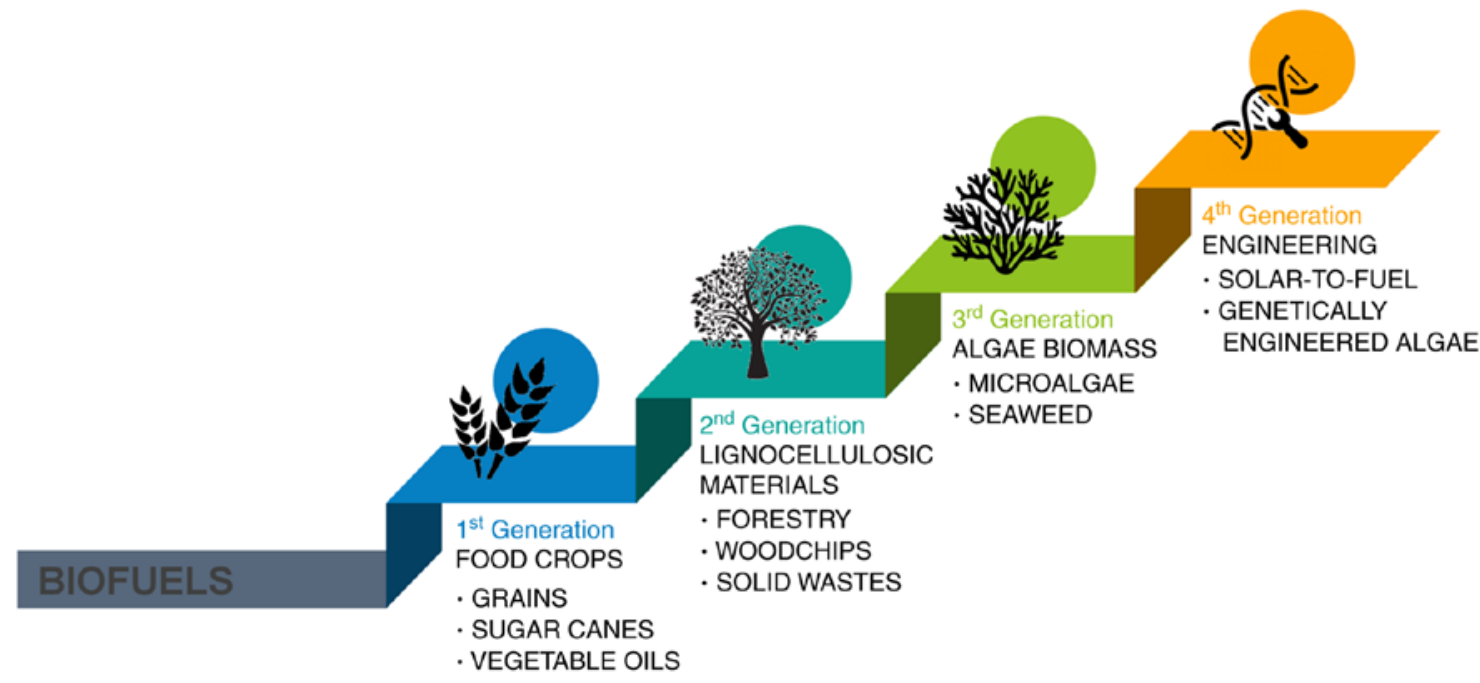

Figure 1. Biofuels and their different generations depending on their origin and production method.

\section{Biobatteries}

When it comes to environmental biotechnology and the introduction of 'greener' energy, a brief mention should also be made of biobatteries, such as microbial fuel cells (MFCs). After being disposed of, traditional batteries, such as one-use AA alkaline batteries used in numerous household appliances and rechargeable lithium batteries used in modern consumer electronic products can be considered as hazardous waste. This fact is mainly due to the potential leaching of toxic materials to the ecosystem $(80,81)$. Moreover, nickel, a metal used for the production of batteries has been implicated in multiple respiratory system conditions, from mild irritations to cancer. Nickel has been shown to alter DNA methylation with a prime example being the hypermethylation of the $O-6$-methylguanine-DNA methyltransferase (MGMT) promoter, a condition associated with lung cancer. Furthermore, nickel exposure has been shown to affect the general levels of histone modifications, implying a severe and global gene expression deregulation (82). Biobatteries or biological fuel cells are electro-biochemical devices that convert organic compounds, such as glucose and starch to electricity through the use of low-cost bio-catalyst enzymes and microorganisms (83). Such batteries are highly safe and biodegradable alternatives to traditional batteries. Research on biobatteries, though, is in its early stages and some technical issues, such as long-term stability need to be overcome (84).

\section{Current applications of 'green' products}

The majority of these 'green' products have been shown to have several market applications. Biodiesel may be the optimal example of a 'green' product that already competes with traditional products on the market level. Biodiesel blends, which include a mixture of pure biodiesel and petrodiesel are useable in any diesel engine, with pure biodiesel being usable through the installation of a heating system. Biodiesel is currently produced at the million gallons level annually by industrial facilities and by small manufacturers that produce it from used cooking oil (85). Biolubricants, which address the environmental and health concerns of traditional lubricants, have also exhibited an increase in consumption with a prime example being that $4 \%$ of 1.05 million tons of the total lubricants in 2005 in Germany were biolubricant, with their use increasing rapidly (86). Recent technological advancements have also demonstrated that biobatteries, such as bacteria-powered ones, can be an excellent energy source for low-power battery-reliant devices, since they are stand-alone device platforms that can be used in resource-limited and remote regions (87). Bioplastics have also displayed several market applications with the most common ones being packaging material, and carrier and compost bags. It should also be mentioned that biodegradable polymers have been a mainstay of biomedicine (88). Lastly, biobased solvents also seem to display an increase in use. Specifically, the global annual global solvent market is $\sim 20$ million metric tons, with biobased solvents being estimated to amount to one million metric tons in Europe (89).

\section{Conclusions and future perspectives}

The environmental footprint has been a major concern over the past decades in terms of the global economy, environmental health and human health. Fossil resources that have served human needs for a long period of time have been responsible for the detrimental effects on the planet. The destabilization of the environment and the accumulation of waste have multiple negative impacts on humans, not only as direct health issues, but also in an epigenetic perspective. The resources used for energy production, and high-waste energy and resources consumption have caused alterations in the stability of the human ecosystem, altering the chemical composition of the environment and affecting the exposome; thus, the genetic and epigenetic mechanisms that control or deregulate human physiology have also been affected. For example, the overgrowing use of plastics, and the chemicals derived, have been shown to promote disease by modifying epigenetic patterns. Moreover, fossil resources are finite, and thus, the dependence on these for such a large part of everyday activity is not sustainable. These facts led to 21st century scientists turning towards technologies with a small environmental footprint. These technologies range from the use of materials of biological origin in everyday products to biofuels and biobatteries for energy consumption (Table I). What characterizes such technologies is 
Table I. List of traditional chemical products and their corresponding alternatives.

Currently used product

‘Green' alternatives

Petroleum-derived industrial solvents

Petroleum-derived lubricants

Non-biodegradable petroleum-derived plastics

Fossil fuels

Batteries (alkaline and lithium-based)
Alcohols (1-butanol, octan-2-ol, propane-1,3-diol), Ethyl lactate

Natural vegetable oils (rice bran oil, rapeseed oil, coconut oil)

Bioplastics (polycaprolactone, polybutylene succinate, polybutylene adipate, polylactic acid, polyhydroxyalkanoates, succinic acid, 1,3-propanediol based polymers, cellulose, starch, biobased polyethylene terephthalate, biobased polyethylene)

Biofuels (bioethanol, biomethane, biodiesel, biobutanol)

Biobatteries (microbial fuel cells)

Table II. Advantages and disadvantages of the use of traditional chemical products and bio-materials.

\begin{tabular}{lll}
\hline & \multicolumn{1}{c}{ Advantages } & \multicolumn{1}{c}{ Disadvantages } \\
\hline Chemical products & $\begin{array}{l}\text { Already existing technology allows mass } \\
\text { production }\end{array}$ & $\begin{array}{l}\text { Harmful to the environment } \\
\text { Harmful to human health }\end{array}$ \\
& Cost-effective & Finite resources \\
Biomaterials & Eco-friendly & More research required for mass and safe production \\
& Little to no harmful effects on human health & Expensive products \\
& Renewable resources & Large initial investment needed
\end{tabular}

that their promise of 'greener' alternatives is not an easy task, even though the raw materials used are renewable natural resources. The majority of the occurring issues amount to the complex mechanisms through which a product can influence the environment since, at times, the current production process may be very energy-intensive and may thus provide no actual benefit against fossil-based products. Another issue is the economic viability of a product. The majority of 'green' alternative production processes require large investments, and the end-product may be costly. These differences in advantages and disadvantages (Table II) between 'traditional' products and their 'greener' alternatives are the reason why ecofriendly products are yet to surpass the production and the use of products harmful to both the environment and human health. Thus, further research is required to develop products that are both cost-effective, safe for use, and their entire production process is environmentally friendly.

\section{Acknowledgements}

Not applicable.

\section{Funding}

The authors would like to acknowledge funding from the following organizations: i) AdjustEBOVGP-Dx (RIA2018EF-2081): Biochemical Adjustments of native EBOV Glycoprotein in Patient Sample to Unmask target Epitopes for Rapid Diagnostic Testing. A European and Developing Countries Clinical Trials Partnership (EDCTP2) under the Horizon 2020 'Research and Innovation Actions' DESCA; and ii) 'MilkSafe: A novel pipeline to enrich formula milk using omics technologies', a research co-financed by the European Regional Development Fund of the European Union and Greek national funds through the Operational Program Competitiveness, Entrepreneurship and Innovation, under the call RESEARCH-CREATE-INNOVATE (project code: T2EDK-02222).

\section{Availability of data and materials}

Not applicable.

\section{Authors' contributions}

All authors (EP, TM, KD, AE, FB, GPC, EE and DV) contributed to conceptualization, writing, drafting, revising, editing and reviewing of the manuscript. All authors confirm the authenticity of all the raw data. All authors have read and approved the final manuscript.

\section{Ethics approval and consent to participate}

Not applicable.

\section{Patient consent for publication}

Not applicable.

\section{Competing interests}

GPC is the Editor in Chief of the journal, and DV and EE are Editors of the journal. However, they had no personal 
involvement in the reviewing process, or any influence in terms of adjudicating on the final decision, for this article. The other authors declare that they have no competing interests.

\section{References}

1. Institute of Medicine (US): Roundtable on Environmental Health Sciences, Research, and Medicine. In: Health and the Environment in the Southeastern United States. Frumkin H, Jackson RJ and Coussens CM (eds). Institute of Medicine, Washington, DC, 2002.

2. Chao Q and Feng A: Scientific basis of climate change and its response. Global Energy Interconnection 1: 420-427, 2018.

3. Seymour V: The human-nature relationship and its impact on health: A critical review. Frontiers in Public Health 4: 2016.

4. Wheeler $\mathrm{N}$ and Watts N: Climate change: From science to practice. Curr Environ Health Rep 5: 170-178, 2018.

5. Hathaway J and Maibach EW: Health implications of climate change: A review of the literature about the perception of the public and health professionals. Curr Environ Health Rep 5: 197-204, 2018

6. Verones F, Moran D, Stadler K, Kanemoto K and Wood R Resource footprints and their ecosystem consequences. Sci Rep 7: 40743, 2017.

7. Vanham D, Leip A, Galli A, Kastner T, Bruckner M, Uwizeye A, van Dijk K, Ercin E, Dalin C, Brandão M, et al: Environmental footprint family to address local to planetary sustainability and deliver on the SDGs. Sci Total Environ 693: 133642, 2019.

8. Greally JM: A user's guide to the ambiguous word 'epigenetics' Nat Rev Mol Cell Biol 19: 207-208, 2018.

9. Allis CD and Jenuwein T: The molecular hallmarks of epigenetic control. Nat Rev Genet 17: 487-500, 2016.

10. Ho SM, Johnson A, Tarapore P, Janakiram V, Zhang X and Leung YK: Environmental epigenetics and its implication on disease risk and health outcomes. ILAR J 53: 289-305, 2012.

11. Balachandar G, Khanna N and Das D: Biohydrogen production from organic wastes by dark fermentation. Biohydrogen: 103-144, 2013.

12. Perera F: Pollution from fossil-fuel combustion is the leading environmental threat to global pediatric health and equity: Solutions Exist. Int J Environ Res Public Health 15: 16, 2017.

13. Armaroli $\mathrm{N}$ and Balzani V: The legacy of fossil fuels. Chem Asian J 6: 768-784, 2011.

14. Anderson TR, Hawkins E and Jones PD: $\mathrm{CO}_{2}$, the greenhouse effect and global warming: From the pioneering work of Arrhenius and Callendar to today's Earth System Models. Endeavour 40: 178-187, 2016.

15. Roundtable NRCCS: The National Academies Collection: Reports funded by National Institutes of Health. In: Carbon Management: Implications for R\&D in the Chemical Sciences and Technology: A Workshop Report to the Chemical Sciences Roundtable. National Academies Press, National Academy of Sciences, Washington, DC, 2001.

16. Hopewell J, Dvorak R and Kosior E: Plastics recycling: Challenges and opportunities. Philos Trans R Soc Lond B Biol Sci 364: 2115-2126, 2009

17. Thompson RC, Moore CJ, vom Saal FS and Swan SH: Plastics, the environment and human health: current consensus and future trends. Philos Trans R Soc Lond B Biol Sci 364: 2153-2166, 2009.

18. Klemeš JJ, Fan YV, Tan RR and Jiang P: Minimising the present and future plastic waste, energy and environmental footprints related to COVID-19. Renew Sustain Energy Rev 127: 109883-109883, 2020.

19. Chianese R, Troisi J, Richards S, Scafuro M, Fasano S, Guida M, Pierantoni R and Meccariello R: Bisphenol A in reproduction: Epigenetic effects. Curr Med Chem 25: 748-770, 2018.

20. Manikkam M, Tracey R, Guerrero-Bosagna $C$ and Skinner MK: Plastics derived endocrine disruptors (BPA, DEHP and DBP) induce epigenetic transgenerational inheritance of obesity, reproductive disease and sperm epimutations. PLoS One 8: e55387, 2013.

21. Demeneix BA: Evidence for prenatal exposure to thyroid disruptors and adverse effects on brain development. Eur Thyroid $\mathrm{J} 8$ : 283-292, 2019.

22. Engdahl E, Svensson K, Lin PD, Alavian-Ghavanini A, Lindh C, Ruegg $\mathbf{J}$ and Bornehag CG: DNA methylation at GRIN2B partially mediates the association between prenatal bisphenol $\mathrm{F}$ exposure and cognitive functions in 7-year-old children in the SELMA study. Environ Int 156: 106617, 2021.
23. Cimmino I, Fiory F, Perruolo G, Miele C, Beguinot F, Formisano $\mathrm{P}$ and Oriente F: Potential Mechanisms of Bisphenol A (BPA) contributing to human disease. Int J Mol Sci 21: 2020

24. Ma Y, Xia W, Wang DQ, Wan YJ, Xu B, Chen X, Li YY and Xu SQ: Hepatic DNA methylation modifications in early development of rats resulting from perinatal BPA exposure contribute to insulin resistance in adulthood. Diabetologia 56: 2059-2067, 2013.

25. Provvisiero DP, Pivonello C, Muscogiuri G, Negri M, de Angelis C, Simeoli C, Pivonello R and Colao A: Influence of bisphenol A on type 2 diabetes mellitus. Int J Environ Res Public Health 13: 989, 2016.

26. Shafei A, Ramzy MM, Hegazy AI, Husseny AK, El-Hadary UG, Taha MM and Mosa AA: The molecular mechanisms of action of the endocrine disrupting chemical bisphenol A in the development of cancer. Gene 647: 235-243, 2018.

27. Doherty LF, Bromer JG, Zhou Y, Aldad TS and Taylor HS: In utero exposure to diethylstilbestrol (DES) or bisphenol-A (BPA) increases EZH2 expression in the mammary gland: an epigenetic mechanism linking endocrine disruptors to breast cancer. Horm Cancer 1: 146-155, 2010.

28. Wehbe Z, Nasser SA, El-Yazbi A, Nasreddine S and Eid AH: Estrogen and bisphenol A in hypertension. Curr Hypertens Rep 22: 23, 2020.

29. Hamza M, Halayem S, Mrad R, Bourgou S, Charfi F and Belhadj A: Epigenetics' implication in autism spectrum disorders: A review. Encephale 43: 374-381, 2017 (In French).

30. Gupta V, Sengupta M, Prakash J and Tripathy B: An introduction to biotechnology. In: Basic and Applied Aspects of Biotechnology. Springer, Singapore, 2017.

31. Hesham Ael L, Ralebitso-Senior TK, Zhang Y and Li QX: Environmental biotechnology: Current advances, new knowledge gaps, and emerging issues. Biomed Res Int 2015: 814529, 2015.

32. National Research Council: Committee on Biomolecular Materials and Processes: From Molecules to Materials to Machines. National Academies Press, Washington, DC, 2008.

33. Welton T: Solvents and sustainable chemistry. Proc Math Phys Eng Sci 471: 20150502, 2015

34. de Marco BA, Rechelo BS, Tótoli EG, Kogawa AC and Salgado HRN: Evolution of green chemistry and its multidimensional impacts: A review. Saudi Pharm J 27: 1-8, 2019.

35. Blossom SJ and Gilbert KM: Epigenetic underpinnings of developmental immunotoxicity and autoimmune disease. Curr Opin Toxicol 10: 23-30, 2018

36. Calvo-Flores FG, Monteagudo-Arrebola MJ, Dobado JA and Isac-García J: Green and Bio-Based Solvents. Topics in current chemistry (Cham) 376: 18, 2018.

37. Tobiszewski M: Analytical chemistry with biosolvents. Anal Bioanal Chem 411: 4359-4364, 2019.

38. Nowak P, Kucharska K and Kamiński M: Ecological and health effects of lubricant oils emitted into the environment. Int J Environ Res Public Health 16: 3002, 2019.

39. IARC monographs on the evaluation of carcinogenic risks to humans. Diesel and gasoline engine exhausts and some nitroarenes. International Agency for Research on Cancer. IARC Monogr Eval Carcinog Risks Hum 46: 1-458, 1989.

40. Wang Y, Zhou Q, Peng S, Ma LQ and Niu X: Toxic effects of crude-oil-contaminated soil in aquatic environment on Carassius auratus and their hepatic antioxidant defense system. J Environ Sci (China) 21: 612-617, 2009.

41. AhmedNSand NassarAM:Lubricating oiladditives.In:TribologyLubricants and Lubrication. Kuo CH (ed). IntechOpen, 2011.

42. Wang B, Zhong Z, Qiu H, Chen D, Li W, Li S and Tu X: Nano serpentine powders as lubricant additive: Tribological behaviors and self-repairing performance on worn surface. Nanomaterials (Basel) 10: 922, 2020

43. Keil KP and Lein PJ: DNA methylation: A mechanism linking environmental chemical exposures to risk of autism spectrum disorders? Environ Epigenet 2: dvv012, 2016.

44. Shi SC and Lu FI: Biopolymer green lubricant for sustainable manufacturing. Materials (Basel) 9: 338, 2016.

45. Esquivel-Gaon M, Nguyen NH, Sgroi MF, Pullini D, Gili F, Mangherini D, Pruna AI, Rosicka P, Sevcu A and Castagnola V: In vitro and environmental toxicity of reduced graphene oxide as an additive in automotive lubricants. Nanoscale 10: 6539-6548, 2018.

46. The future of plastic. Nat Commun 9: 2157, 2018.

47. Geyer R, Jambeck JR and Law KL: Production, use, and fate of all plastics ever made. Sci Adv 3: e1700782, 2017.

48. Danso D, Chow J and Streit WR: Plastics: Environmental and biotechnological perspectives on microbial degradation. Appl Environ Microbiol 85: e01095-19, 2019. 
49. Yang CZ, Yaniger SI, Jordan VC, Klein DJ and Bittner GD Most plastic products release estrogenic chemicals: A potential health problem that can be solved. Environ Health Perspect 119: 989-996, 2011.

50. Rattan S and Flaws JA: The epigenetic impacts of endocrine disruptors on female reproduction across generationsdagger. Biol Reprod 101: 635-644, 2019.

51. Andreeßen C and Steinbüchel A: Recent developments in non-biodegradable biopolymers: Precursors, production processes, and future perspectives. Appl Microbiol Biotechnol 103: 143-157, 2019.

52. Narancic T, Cerrone F, Beagan N and O'Connor KE: Recent advances in bioplastics: Application and biodegradation. Polymers (Basel) 12: 920, 2020.

53. Endres HJ: Bioplastics. Adv Biochem Eng Biotechnol 166: 427-468, 2019.

54. Prieto A: To be, or not to be biodegradable that is the question for the bio-based plastics. Microb Biotechnol 9: 652-657, 2016.

55. Ciriminna R and Pagliaro M: Biodegradable and compostable plastics: A critical perspective on the dawn of their global adoption. ChemistryOpen 9: 8-13, 2020.

56. Gan $\mathrm{Z}$ and Zhang H: PMBD: A comprehensive plastics microbial biodegradation database. Database (Oxford) 2019: baz119, 2019.

57. Ru J, Huo Y and Yang Y: Microbial degradation and valorization of plastic wastes. Front Microbiol 11: 2020.

58. Ganesan R, Manigandan S, Samuel MS, Shanmuganathan R, Brindhadevi K, Lan Chi NT, Duc PA and Pugazhendhi A: A review on prospective production of biofuel from microalgae. Biotechnol Rep (Amst) 27: e00509, 2020

59. Kim EJ, Kim S, Choi H-G and Han SJ: Co-production of biodiesel and bioethanol using psychrophilic microalga Chlamydomonas sp. KNM0029C isolated from Arctic sea ice. Biotechnol Biofuels 13: 20, 2020.

60. Valdivia M, Galan JL, Laffarga J and Ramos JL: Biofuels 2020: Biorefineries based on lignocellulosic materials. Microb Biotechnol 9: 585-594, 2016.

61. Li X, Zheng Y, Guan C, Cheung CS and Huang Z: Effect of biodiesel on PAH, OPAH, and NPAH emissions from a direct injection diesel engine. Environ Sci Pollut Res Int 25 34131-34138, 2018.

62. Aro EM: From first generation biofuels to advanced solar biofuels. Ambio 45 (Suppl 1): S24-S31, 2016.

63. Mohr A and Raman S: Lessons from first generation biofuels and implications for the sustainability appraisal of second generation biofuels. Energy Policy 63: 114-122, 2013.

64. Tapia Carpio LG and Simone de Souza F: Competition between second-generation ethanol and bioelectricity using the residual biomass of sugarcane: Effects of uncertainty on the production mix. Molecules 24: 369, 2019.

65. Hein L and Leemans R: The impact of first-generation biofuels on the depletion of the global phosphorus reserve. Ambio 41: 341-349, 2012

66. Sims RE, Mabee W, Saddler JN and Taylor M: An overview of second generation biofuel technologies. Bioresour Technol 101: $1570-1580,2010$

67. Ho DP, Ngo HH and Guo W: A mini review on renewable sources for biofuel. Bioresour Technol 169: 742-749, 2014.

68. Liu D, Zou C and Xu M: Environmental, ecological, and economic benefits of biofuel production using a constructed wetland: A case study in China. Int J Environ Res Public Health 16: 827, 2019.

69. Ramos JL, Valdivia M, García-Lorente F and Segura A: Benefits and perspectives on the use of biofuels. Microb Biotechnol 9: 436-440, 2016

70. Balan V: Current challenges in commercially producing biofuels from lignocellulosic biomass. ISRN Biotechnol 2014: 463074, 2014.
71. Neto JM, Komesu A, Da Silva Martins LH, Goncalves VO, De Oliveira JA and Rai M: Third-generation biofuels: An overview. In: Sustainable Biofuel and Biomass. Apple Academic Press, 2019.

72. Bleakley S and Hayes M: Algal proteins: Extraction, application, and challenges concerning production. Foods 6: 33, 2017.

73. Khoo CG, Dasan YK, Lam MK and Lee KT: Algae biorefinery: Review on a broad spectrum of downstream processes and products. Bioresour Technol 292: 121964, 2019.

74. Behera S, Singh R, Arora R, Sharma NK, Shukla M and Kumar S: Scope of algae as third generation biofuels. Front Bioeng Biotechnol 2: 90, 2015.

75. Shurin JB, Burkart MD, Mayfield SP and Smith VH: Recent progress and future challenges in algal biofuel production. F1000Res 5: F1000, 2016.

76. Hannon M, Gimpel J, Tran M, Rasala B and Mayfield S: Biofuels from algae: Challenges and potential. Biofuels 1: 763-784, 2010.

77. Lü J, Sheahan C and Fu P: Metabolic engineering of algae for fourth generation biofuels production. Energy Environ Sci 4: 2451-2466, 2011

78. Bhardwaj S, Kumar S and Arora R: Bioprospecting of microorganisms for biofuel production. In: Biofuels ProductionSustainability and Advances in Microbial Bioresources. Biofuel and Biorefinery Technologies. Vol 11. Yadav A, Rastegari A, Yadav N and Gaur R (eds). Springer, New York, NY, 2020.

79. Moravvej Z, Makarem MA and Rahimpour MR: Chapter 20-The fourth generation of biofuel. In: Second and Third Generation of Feedstocks. Basile A and Dalena F (eds). Elsevier, Amsterdam, pp557-597, 2019.

80. Xará SM, Delgado JN, Almeida MF and Costa CA: Laboratory study on the leaching potential of spent alkaline batteries. Waste Manag 29: 2121-2131, 2009.

81. Kang DH, Chen M and Ogunseitan OA: Potential environmental and human health impacts of rechargeable lithium batteries in electronic waste. Environ Sci Technol 47: 5495-5503, 2013.

82. Martinez-Zamudio R and Ha HC: Environmental epigenetics in metal exposure. Epigenetics 6: 820-827, 2011.

83. Cheng K, Zhang F, Sun F, Chen $\mathrm{H}$ and Percival Zhang $\mathrm{YH}$ : Doubling power output of starch biobattery treated by the most thermostable isoamylase from an Archaeon Sulfolobus tokodaii. Sci Rep 5: 13184, 2015.

84. Zhu Z, Kin Tam T, Sun F, You C and Percival Zhang YH: A high-energy-density sugar biobattery based on a synthetic enzymatic pathway. Nat Commun 5: 3026, 2014.

85. Schmidt CW: Biodiesel: Cultivating alternative fuels. Environ Health Perspect 115: A86-A91, 2007.

86. Aziz NAM, Yunus R, Hamid HA, Ghassan AAK, Omar R, Rashid U and Abbas Z: An acceleration of microwave-assisted transesterification of palm oil-based methyl ester into trimethylolpropane ester. Sci Rep 10: 19652, 2020.

87. Gao Y, Mohammadifar M and Choi S: From microbial fuel cells to biobatteries: Moving toward on-demand micropower generation for small-scale single-use applications. Adv Materials Technol 4: 1900079, 2019.

88. Di Bartolo A, Infurna G and Dintcheva NT: A review of bioplastics and their adoption in the circular economy. Polymers (Basel) 13: 1229, 2021.

89. Dong X, Al-Jumaily A and Escobar IC: Investigation of the use of a bio-derived solvent for non-solvent-induced phase separation (NIPS) fabrication of polysulfone membranes. Membranes (Basel) 8: 23, 2018.

This work is licensed under a Creative Commons Attribution-NonCommercial 4.0 International (CC BY-NC 4.0) License. 